Gazi University
Journal of Science
http://dergipark.gov.tr/gujs

\title{
Comparison of Hot-rolled Unalloyed Magnesium and Magnesium Alloys in terms of Biodegradability and Mechanical Properties
}

\author{
Alper INCESU ${ }^{1, *(1)}$, Ali GUNGOR ${ }^{2}$ \\ ${ }^{I}$ Karabuk University, TOBB Tech. Sciences Vocational School, 78050, Karabuk, Turkey \\ ${ }^{2}$ Karabuk University, Metallurgical and Materials Engineering, 78050, Karabuk, Turkey
}

\section{Highlights}

- Pure magnesium, ZXM100 and ZXM120 alloys were fabricated.

- Bio-corrosion and mechanical properties were investigated.

- ZXM100 can be applied as a biomaterial.

\section{Article Info}

Received: 12 Nov 2020 Accepted: 13 Sep 2021

\section{Keywords}

\section{Mg Alloys}

Hot rolled

Biodegradability

Tensile properties

\begin{abstract}
In this study, hot rolling is properly performed on pure magnesium and two of $\mathrm{Zn}, \mathrm{Ca}$ and $\mathrm{Mn}$ containing magnesium alloys. Biodegradability and mechanical properties are investigated comparatively in their rolled state. While the average grain sizes of the two alloys were close to each other, it was observed that the $\mathrm{Mg}-1.01 \mathrm{Zn}-1.63 \mathrm{Ca}-0.30 \mathrm{Mn}$ alloy had higher hardness $(61.5$ $\pm 0.2 \mathrm{HV}$ ) at hot rolled state. The lowest corrosion rate in electrochemical corrosion test on $\mathrm{Mg}$ $1.07 \mathrm{Zn}-0.21 \mathrm{Ca}-0.31 \mathrm{Mn}$ alloy is observed to be $1.772 \mathrm{~mm} / \mathrm{yr}$. As for the immersion corrosion test on the same alloy, the lowest corrosion rate is detected to be $0.054 \mathrm{~mm} / \mathrm{yr}$. Moreover, $\mathrm{Mg}-1.07 \mathrm{Zn}$ $0.21 \mathrm{Ca}-0.31 \mathrm{Mn}$ alloy has the highest tensile strength. Based on the results, it is ascertained that hot-rolled Mg-1.07Zn-0.21Ca-0.31Mn alloy possesses a better biodegradability and mechanical properties compared to hot rolled commercially unalloyed $\mathrm{Mg}$ and $1.01 \mathrm{Zn}-1.63 \mathrm{Ca}-0.30 \mathrm{Mn}$ alloy.
\end{abstract}

\section{INTRODUCTION}

There are many different types of materials such as metals and metal alloys, ceramics, and plastics to be used as biomaterials. Metals can be applied in much wider service conditions than plastics and ceramics due to their high strength and toughness [1]. One of important properties for implant biomaterials is biodegradability thanks to which further surgical procedures are avoided and long-term complications are reduced [2]. When considering biodegradability, magnesium $(\mathrm{Mg})$ stands out with its easy degradation and non-toxic degradation products in environments containing Cl- ions [3,4]. However, due to the rapid and irregular degradation of unalloyed magnesium in body fluid environment, utilizing it as a biodegradable implant material in its pure form is hardly applicable. Because of that, it is inevitable to alloy pure $\mathrm{Mg}$ with harmless alloying elements and apply thermal and thermomechanical processes [5]. Therefore, many binary, ternary, and quaternary magnesium-based alloy systems have been designed and developed, and also continue to be developed to date. [6-8]. $\mathrm{Mg}-\mathrm{Zn}-\mathrm{Ca}-\mathrm{Mn}$ as quaternary magnesium alloys have been evolved nowadays for biomedical applications thanks to their low production costs, improved mechanical properties, and moderate corrosion resistance [9-11].

The daily intake limit of $\mathrm{Mg}, \mathrm{Zn}$, and $\mathrm{Ca}$ are $700 \mathrm{mg}, 15 \mathrm{mg}$ and $800 \mathrm{mg}$ for adults, respectively. Overdose of $\mathrm{Zn}$ results in Zinc deficiency. Zinc deficiency brings about growth and developmental delay, impaired parturition (dystocia), hypotension, bleeding tendencies, neuropathy, diarrhea, dermatitis, hair loss, poor appetite, and hypothermia. Excessive amount of $\mathrm{Mg}$ provokes nausea. Overdose of $\mathrm{Ca}$ hinders the absorption of other essential minerals by intestines [12].

In addition to alloying, surface treatment techniques such as coating can be utilized for the purpose of enhancing the corrosion resistance of magnesium alloys. Bordbar-Khiabani et. al [13] identify the impact 
of the acute inflammatory response on the electrochemical corrosion behavior of uncoated AZ91 $\mathrm{Mg}$ alloy, $\mathrm{PEO}$, and $\mathrm{PEO} / \mathrm{BSP}$ coatings. $\mathrm{PEO} / \mathrm{BSP}$ coating is detected to supply more observable protection when it is compared to the simple PEO coating. In another study, Bordbar-Khiabani et al. [14] indicate that the duplex coating of ZPSL/PEO functions as a critical process in upgrading the anti-corrosional and in-vitro bioactivistic character of $\mathrm{Mg}$. Whereas the study provides such successful results that the coating has a limited thickness on the substrate material constitutes the major disadvantage of it. Therefore, it is predicted that it will be much more efficient to make an implant material from a magnesium alloy that is uncoated, homogeneous and has a stable degradation rate.

In this study, exclusively designed two of $\mathrm{Mg}-\mathrm{Zn}$-Ca-Mn magnesium alloys were fabricated to function as biodegradable materials for fracture bone plate application without surface treatment application. Hot rolling after homogenization heat treatment was administered to the alloys following casting. By applying hot rolling to alloys after homogenization heat treatment, revealing their combined effects on their mechanical and biodegradability properties was targeted. In addition, unalloyed magnesium was produced as reference material by the same method, and it was subjected to the same heat treatment and thermomechanical processes.

\section{MATERIALS \& METHOD}

Unalloyed $\mathrm{Mg}$ as reference material and two distinctive $\mathrm{Mg}-\mathrm{Zn}$-Ca-Mn magnesium alloys were fabricated by gravity casting into a mold produced by hot work tool steel. Chemical compositions of them were given in Table 1. Homogenization heat-treated alloys were examined and their results were published in a previous study [15].

Table 1. Results of XRF analysis for unalloyed Mg and the alloys (wt. \%) [15]

\begin{tabular}{|l|l|l|l|l|}
\hline Designation & $\mathrm{Zn}$ & $\mathrm{Ca}$ & $\mathrm{Mn}$ & $\mathrm{Mg}$ \\
\hline F-Mg & - & - & - & 99.99 \\
\hline ZXM100 & 1.07 & 0.21 & 0.31 & Balanced \\
\hline ZXM120 & 1.01 & 1.63 & 0.30 & Balanced \\
\hline
\end{tabular}

The details of the casting system, mold design and heat treatment are extensively explained in the previous study [15].

Rolling was carried out at a speed of $20 \mathrm{rpm}$ in a twin roll rolling mill with a roller diameter of $200 \mathrm{~mm}$. A total of 30\% deformation was executed in 3 passes, with $10 \%$ deformation at each pass to all samples that had $4.5 \mathrm{~mm}$ initial thicknesses. Before the first pass, each sample was heated to $400{ }^{\circ} \mathrm{C}$ and held at this temperature for 30 minutes. Then, samples were kept at $400{ }^{\circ} \mathrm{C}$ temperature for 15 minutes between passes and the next pass was applied.

Microstructure analysis before and after immersion corrosion test was carried out with a Carl Zeiss ULTRA PLUS FESEM (Field Emission Scanning Electron Microscopy). Tensile tests with Zwick/Roell Z600 Universal Test Machine and hardness tests with Q10 A+ QNESS Micro Hardness Test Machine were applied to characterize the mechanical properties of the alloys. The tensile test speed was $2 \mathrm{~mm} / \mathrm{min}$. at $37 \pm 1{ }^{\circ} \mathrm{C}$.

Immersion corrosion tests and electrochemical corrosion tests were applied to bring out the biodegradability performance of the materials. Equipment, test condition and details of potentiodynamic polarization test and also immersion corrosion test were given in previous study [15]. LONZA Hanks' BSS was used as simulated body fluid corrosive media.

\section{RESEARCH FINDINGS AND DISCUSSION}

SEM micrographs of the unalloyed magnesium and alloys were given in Figure 1. ZXM100 and ZXM120 alloys have finer grains when they are compared to F-Mg. Average grain sizes were given in Table 2 . Depending on the alloying elements added in ZXM100 and ZXM120 alloys, a fine grain structure, 
approximately 5 times finer than unalloyed magnesium, was observed from the SEM micrographs of the alloys. Therefore, it can be said that alloying elements refined the average grain size of unalloyed magnesium. Du et al. [16] figured out that the amount of grain refinement amplified as Ca amount amplified in their study with Mg-3Al-xCa alloys. When microstructures of ZXM100 and ZXM120 alloys are compared, it is observed that a hollow structure is formed in ZXM120 alloy. The reason for this is that the ZXM120 alloy consists of a divorced eutectic $\left(\alpha-\mathrm{Mg}+\mathrm{Ca}_{2} \mathrm{Mg}_{6} \mathrm{Zn}_{3}+\mathrm{Mg}_{2} \mathrm{Ca}\right)$ phase since the $\mathrm{Zn} / \mathrm{Ca}$ ratio is less than 1.2 at.\% [17]. Since electrochemical potentials of the phases are as $\mathrm{Ca}_{2} \mathrm{Mg}_{6} \mathrm{Zn}_{3}>\alpha-\mathrm{Mg}>\mathrm{Mg}_{2} \mathrm{Ca}$ [18], the $\mathrm{Mg}_{2} \mathrm{Ca}$ phase together with the grain boundaries reacted with the etchant during the etching and caused such a hollow like structure.

Table 2 shows the hardness test results of unalloyed magnesium and alloys. The hardness of unalloyed magnesium increased by about $60 \%$ by alloying. When the ZXM100 and ZXM120 alloys are compared, it was determined that the hardness of the ZXM120 alloy is higher than the ZXM100 ( 1 wt.\%) alloy, since the total amount of alloying elements in the ZXM120 ( 3 wt.\%) alloy is higher.

Table 2. Vickers hardness and average grain sizes of unalloyed magnesium and alloys

\begin{tabular}{|l|l|l|}
\hline Designation & Hardness $[\mathrm{HV}]$ & Average Grain Size $[\mu \mathrm{m}]$ \\
\hline F-Mg & $35.7 \pm 0.6$ & 102 \\
\hline ZXM100 & $56.9 \pm 1.2$ & 21 \\
\hline ZXM120 & $61.5 \pm 0.2$ & 18 \\
\hline
\end{tabular}
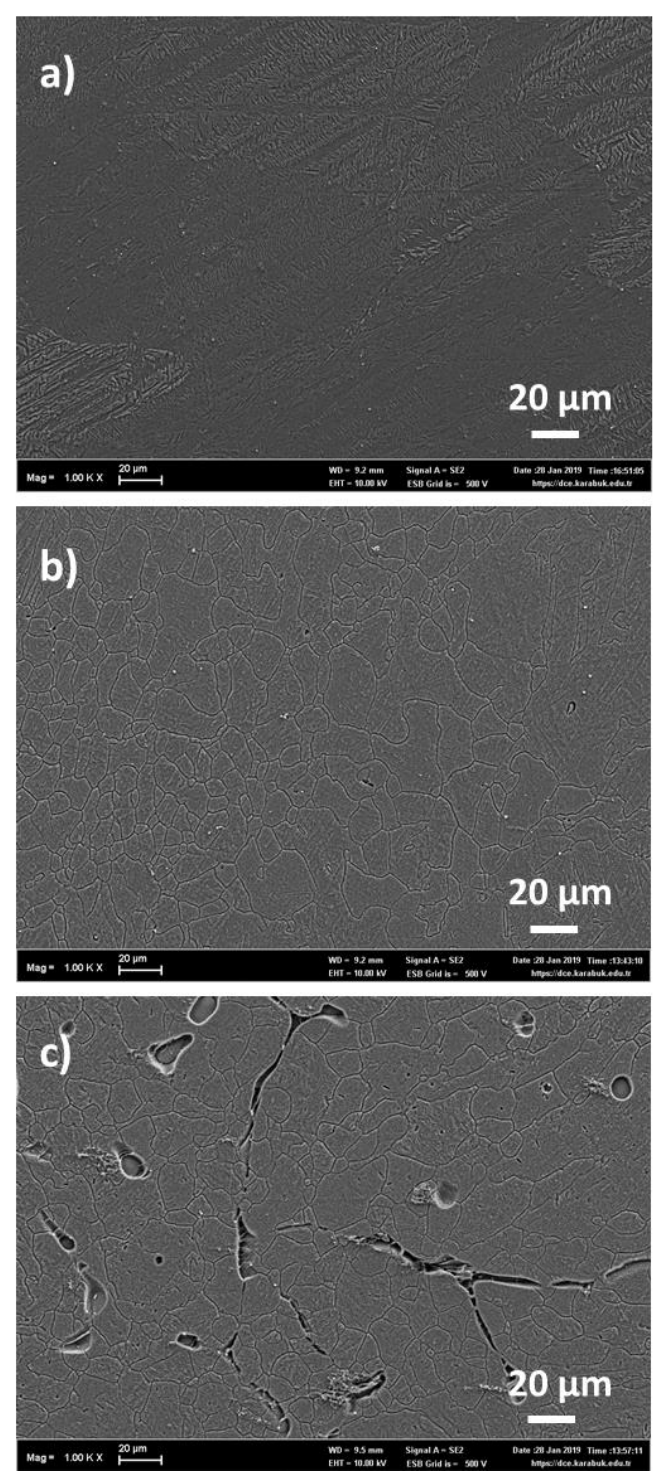

Figure 1. Scanning Electron Microscope images of a) F-Mg b) ZXM100 c) ZXM120 after hot rolling 
Tensile test results of the unalloyed magnesium and alloys were given in Table 3 and stress vs. strain curves were given in Figure 2. The yield strength of unalloyed magnesium was improved by alloying about $\% 64$. The yield strength of ZXM120 alloy could not be measured because it was fractured before the yield point. This can be attributed to the hollow-like microstructure observed in ZXM120 alloy (Figure 1c) because it reduces the strength of the material by creating stress concentration points [19]. The fact that the tensile strength of the ZXM120 alloy is even below the tensile strength of the unalloyed magnesium supports this argument. In the case of ZXM100 alloy, it was determined that yield and tensile strengths of ZXM100 alloy compared to unalloyed magnesium were improved but its elongation was decreased.

Table 3. Tensile test results of unalloyed $M g$ and alloys

\begin{tabular}{|l|l|l|l|}
\hline Designation & $\mathrm{Rp}_{0,2}[\mathrm{MPa}]$ & $\mathrm{R}_{\mathrm{m}}[\mathrm{MPa}]$ & $\mathrm{A}[\%]$ \\
\hline F-Mg & $83 \pm 1.3$ & $156 \pm 2.4$ & $8.9 \pm 0.4$ \\
\hline ZXM100 & $129 \pm 2.2$ & $194 \pm 3.2$ & $1.3 \pm 0.1$ \\
\hline ZXM120 & - & $96 \pm 1.6$ & $0.2 \pm 0.01$ \\
\hline
\end{tabular}

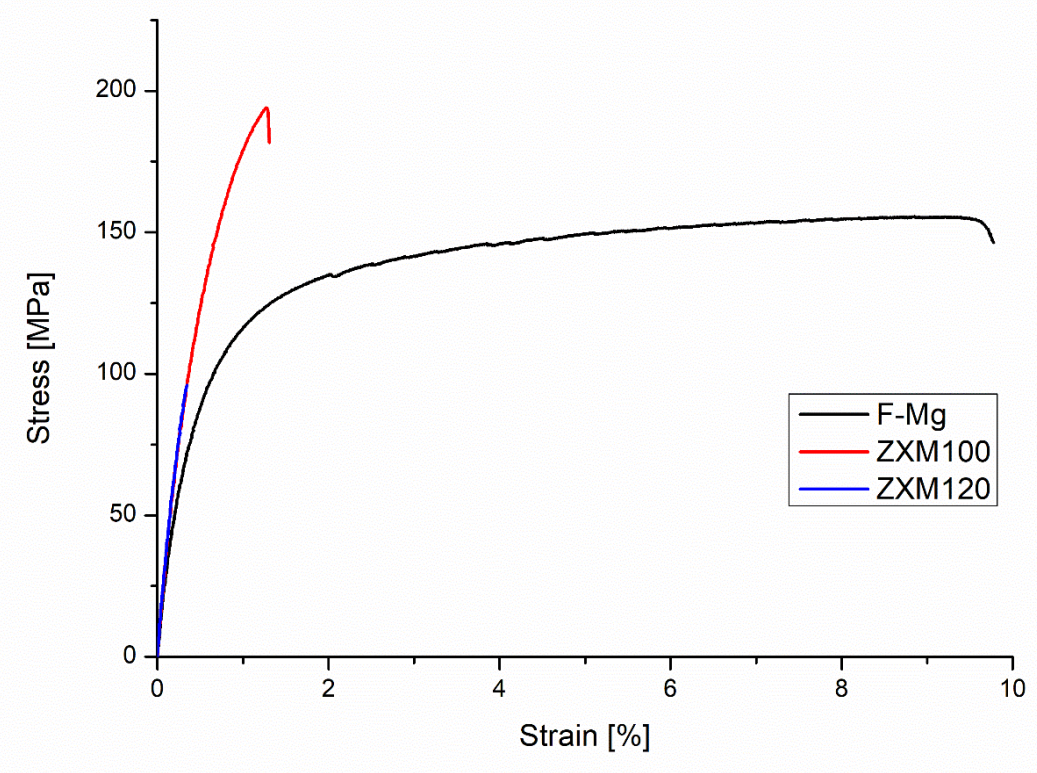

Figure 2. Stress vs Strain curves of unalloyed magnesium and alloys

Electrochemical and immersion corrosion tests were executed to ascertain the biodegradability of samples and results are given in Table 4. Electrochemical and immersion corrosion test results were given in Table 4 and SEM images of corroded surfaces of samples after $48 \mathrm{hrs}$. immersion were given in Figure 3 . The corrosion rates figured out once the electrochemical corrosion test and the immersion corrosion test were consistent with each other.

Table 4. Corrosion rates of the samples

\begin{tabular}{|l|l|l|}
\hline \multirow{2}{*}{ Designation } & \multicolumn{2}{|c|}{ Corrosion Rate (mm/yr.) } \\
\cline { 2 - 3 } & Potentiodynamic polarization test & Immersion test for 48 hrs. \\
\hline F-Mg & 2.279 & 0.405 \\
\hline ZXM100 & 1.772 & 0.054 \\
\hline ZXM120 & 2.223 & 0.331 \\
\hline
\end{tabular}

ZXM100 alloy has the lowest corrosion rate while unalloyed magnesium has the highest corrosion rate in both electrochemical corrosion and $48 \mathrm{hrs}$. immersion corrosion. Despite the increase in the amount of added alloying elements in the ZXM120 alloy, the reason for the increase in the corrosion rate compared to the ZXM100 alloy can be the existence of the $\mathrm{Mg}_{2} \mathrm{Ca}$ intermetallic phase in the structure. 
Due to the low electrochemical potential of this phase $\left(\mathrm{Mg}_{2} \mathrm{Ca}\right), \alpha-\mathrm{Mg}$ is preferably degraded in the alloy. This results in the corrosion progressing rapidly into the alloy (Figure $3 \mathrm{c}$ ). This is seen in the post-corrosion microstructure images given in Figure 3. While the corrosion rate of ZXM100 alloy progressed more regularly, the ZXM120 alloy progressed more irregularly towards the inside of the alloy in the hollow regions due to the $\mathrm{Mg}_{2} \mathrm{Ca}$ phase. Also, during the immersion corrosion test, the surface activity contains a set of reactions which involve ion exchange, precipitation and dissolution [20]. As a result of these activities, cracking and pitting form on the surfaces of the Mg alloys following immersion in SBF solution as demonstrated in Figure $3 \mathrm{~b}$ and Figure 3c.
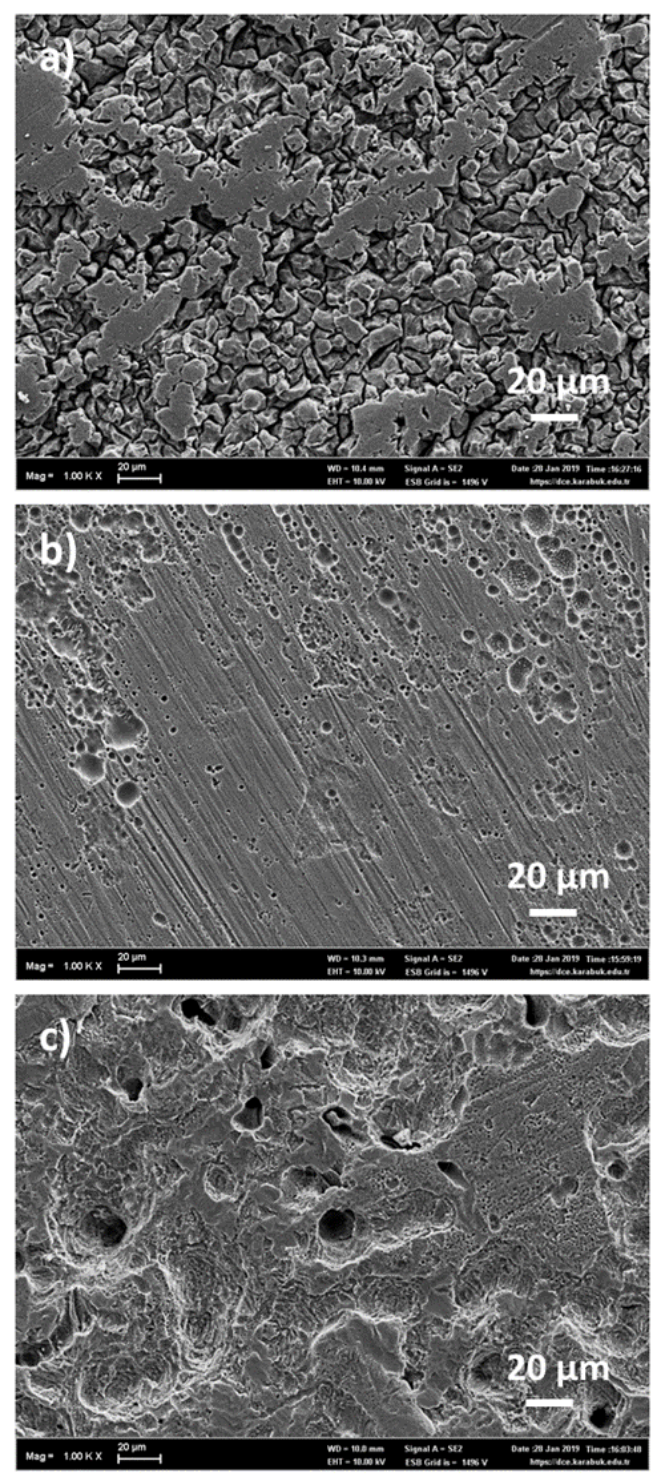

Figure 3. Scanning Electron Microscope images of a) F-Mg b) ZXM100 c) ZXM120 after 48 hrs. immersion corrosion

Figure 4 shows the immersion time vs. corrosion rate graph of F-Mg, ZXM100, ZXM120 alloys. It can be observed that especially F-Mg and ZXM120 alloys show quite aggressive degradation up to about $12 \mathrm{hrs}$. immersion time. This form of degradation can also be seen from the SEM images in Figure 3. 


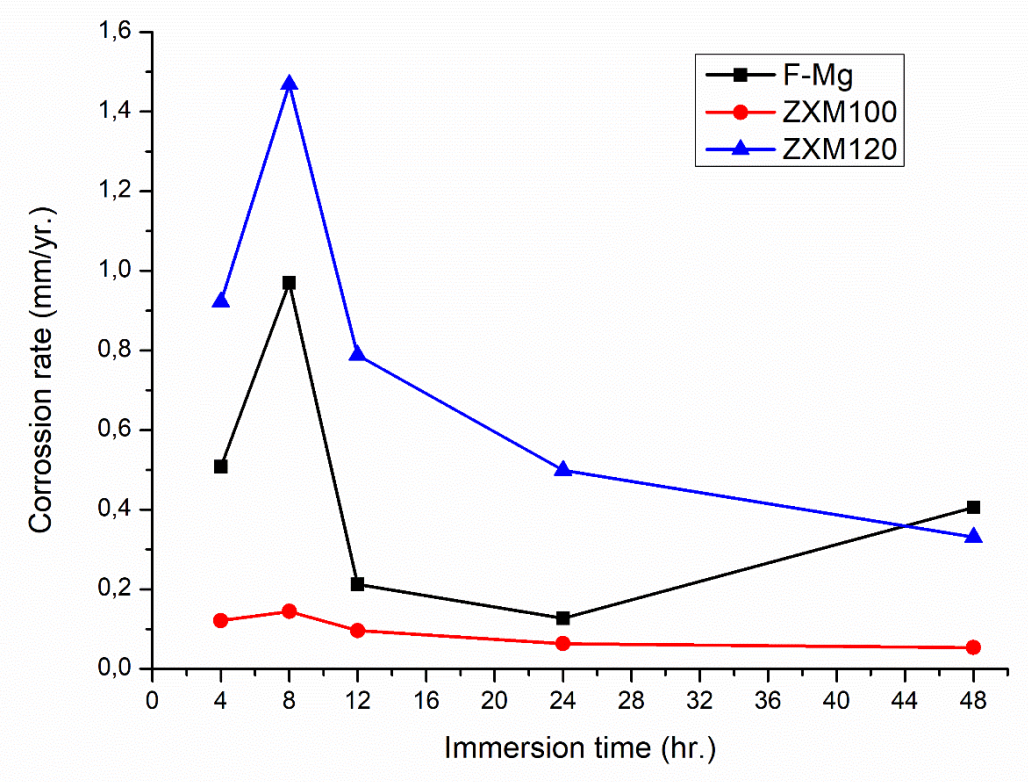

Figure 4. Immersion time vs. corrosion rate graph of F-Mg, ZXM100, ZXM120

In the ZXM100 alloy, a regular degradation pattern (Figure 3b) and a very low rate of decomposition are observed during the entire immersion period (from 4 hours to 48 hours).

As a result, hot rolled ZXM100 alloy containing low proportions of alloying elements without $\mathrm{Mg}_{2} \mathrm{Ca}$ phase in the structure meets the requirements in terms of both mechanical properties and biodegradability properties for fracture bone plate material.

\section{CONCLUSION}

In this study, unalloyed magnesium, ZXM100 and ZXM120 alloys were fabricated by gravity casting. Hot rolling after homogenization heat treatment was applied to all produced materials. Properties of the materials were analyzed comparatively in the hot-rolled state, and the following results were obtained.

- Due to the $\mathrm{Mg}_{2} \mathrm{Ca}$ intermetallic phase in the structure of $\mathrm{Mg}-1.01 \mathrm{Zn}-1.63 \mathrm{Ca}-0.30 \mathrm{Mn}$ alloy, it is lower in both strength properties and biocorrosion properties compared to $\mathrm{Mg}-1.07 \mathrm{Zn}-0.21 \mathrm{Ca}-0.31 \mathrm{Mn}$ alloy.

- The Vickers hardness of the Mg-1.01Zn-1.63Ca-0.30Mn alloy was the highest due to the hardening effect of increased alloying elements.

- Mg-1.07Zn-0.21Ca-0.31Mn alloy can be considered as biodegradable implant material with its improved strength and biodegradability properties.

\section{CONFLICTS OF INTEREST}

No conflict of interest was declared by the authors.

\section{ACKNOWLEDGEMENT}

The paper is presented as an oral presentation in International Conference on Advanced Materials Science \& Engineering and High Tech Devices Applications; Exhibition (ICMATSE 2020), October 2-4, 2020, Gazi University, Ankara, Turkey. 
This study was supported by Scientific Research Projects Coordination Unit of Karabuk University (Project No: KBU-BAP-16/2-DR-100).

\section{REFERENCES}

[1] Gu, X. N., Li, S. S., Li, X. M., and Fan, Y. B., "Magnesium based degradable biomaterials: A review", Frontiers of Materials Science, 8(3): 200-218, (2014).

[2] Tong, L. B., Chu, J. H., Jiang, Z. H., Kamado, S., and Zheng, M. Y., "Ultra-fine grained Mg-ZnCa-Mn alloy with simultaneously improved strength and ductility processed by equal channel angular pressing", Journal of Alloys and Compounds, 785: 410-421, (2019).

[3] Chen, K., Dai, J., and Zhang, X., "Improvement of corrosion resistance of magnesium alloys for biomedical applications", Corrosion Reviews, 33(3-4): 101-117, (2015).

[4] Persaud-Sharma, D. and McGoron, A., "Biodegradable magnesium alloys: a review of material development and applications", Journal of Biomimetics, Biomaterials and Tissue Engineering, 12, 25-39, (2011).

[5] Zheng, L., Nie, H., Liang, W., Wang, H., and Wang, Y., "Effect of pre-homogenizing treatment on microstructure and mechanical properties of hot-rolled AZ91 magnesium alloys", Journal of Magnesium and Alloys, 4(2): 115-122, (2016).

[6] Li, H., Wen, J., Liu, Y., He, J., Shi, H., and Tian, P., "Progress in Research on Biodegradable Magnesium Alloys: A Review", Advanced Engineering Materials, 2000213, (2020).

[7] Jahani, B., Meesterb, K., Wanga, X., and Brooksc, A., "Biodegradable Magnesium-Based Alloys for Bone Repair Applications: Prospects And Challenges", Biomedical Sciences Instrumentation, 56: 2, (2020).

[8] Wang, J. L., Xu, J. K., Hopkins, C., Chow, D. H. K., and Qin, L., "Biodegradable MagnesiumBased Implants in Orthopedics-A General Review and Perspectives", Advanced Science, 7(8): 1902443, (2020).

[9] Nie, K., Zhu, Z., Munroe, P., Deng, K., and Han, J., "The effect of Zn/Ca ratio on the microstructure, texture and mechanical properties of dilute $\mathrm{Mg}-\mathrm{Zn}-\mathrm{Ca}-\mathrm{Mn}$ alloys that exhibit superior strength", Journal of Materials Science, 55(8): 3588-3604, (2020).

[10] Duley, P., Sanyal, S., Bandyopadhyay, T. K., and Mandal, S., "Homogenization-induced agehardening behavior and room temperature mechanical properties of $\mathrm{Mg}-4 \mathrm{Zn}-0.5 \mathrm{Ca}-0.16 \mathrm{Mn}$ (wt $\%)$ alloy", Materials \& Design, 164: 107554, (2019).

[11] Becerra, L. H. C., Rodríguez, M. A. L. H., Esquivel-Solís, H., Arroyo, R. L., and Castro, A. T., "Bio-inspired biomaterial Mg-Zn-Ca: a review of the main mechanical and biological properties of Mg-based alloys", Biomedical Physics \& Engineering Express, 6: 042001, (2020).

[12] Katarivas Levy, G., Goldman, J., and Aghion, E., "The prospects of zinc as a structural material for biodegradable implants—a review paper", Metals, 7(10): 402, (2017).

[13] Bordbar-Khiabani, A., Yarmand, B., Sharifi-Asl, S., and Mozafari, M., "Improved corrosion performance of biodegradable magnesium in simulated inflammatory condition via drug-loaded plasma electrolytic oxidation coatings", Materials Chemistry and Physics, 239: 122003, (2020). 
[14] Bordbar-Khiabani, A., Yarmand, B., and Mozafari, M., "Effect of ZnO pore-sealing layer on anticorrosion and in-vitro bioactivity behavior of plasma electrolytic oxidized AZ91 magnesium alloy", Materials Letters, 258: 126779, (2020).

[15] Incesu, A., and Gungor, A., "Biocorrosion and Mechanical Properties of ZXM100 and ZXM120 Magnesium Alloys", International Journal of Metalcasting, 13(4): 905-914, (2019).

[16] Du, J., Yang, J., Kuwabara, M., Li, W., and Peng, J., "Improvement of grain refining efficiency for $\mathrm{Mg}-\mathrm{Al}$ alloy modified by the combination of carbon and calcium", Journal of Alloys and Compounds, 470(1-2): 134-140, (2009).

[17] Li, H., Qin, S., Ma, Y., Wang, J., Liu, Y., and Zhang, J., "Effects of Zn content on the microstructure and the mechanical and corrosion properties of as-cast low-alloyed $\mathrm{Mg}-\mathrm{Zn}-\mathrm{Ca}$ alloys", International Journal of Minerals, Metallurgy and Materials, 25(7): 800-809, (2018).

[18] Rad, B., Idris, M. H., Kadir, M. R. A., Farahany, S., Fereidouni, A., and Yahya, M. Y., "Characterization and corrosion behavior of biodegradable $\mathrm{Mg}-\mathrm{Ca}$ and $\mathrm{Mg}-\mathrm{Ca}-\mathrm{Zn}$ implant alloys", Applied Mechanics and Materials, 121: 568-572, (2012).

[19] Liu, H., Sun, C., Ce, W., Li, Y., Bai, J., Xue, F., Ma, A., and Jiang, J., "Improving toughness of a $\mathrm{Mg} 2 \mathrm{Ca}$-containing $\mathrm{Mg}-\mathrm{Al}-\mathrm{Ca}-\mathrm{Mn}$ alloy via refinement and uniform dispersion of $\mathrm{Mg} 2 \mathrm{Ca}$ particles", Journal of Materials Science \& Technology, 59: 61-71, (2020).

[20] Bordbar-Khiabani, A., Yarmand, B., and Mozafari, M., "Functional PEO layers on magnesium alloys: innovative polymer-free drug-eluting stents", Surface Innovations, 6(4-5): 237-243, (2018). 